\title{
Influence of Fining and Tartaric Stabilisation Procedures on White Wine Mannoprotein Content
}

\author{
A. Rodrigues ${ }^{1,2}$, J.M. Ricardo-Da-Silva ${ }^{1 *}$, C. Lucas ${ }^{2}$, O. Laureano ${ }^{1}$ \\ (1) Technical University of Lisbon, Instituto Superior de Agronomia, Laboratório Ferreira Lapa (Sector de Enologia), \\ 1349-017 Lisbon, Portugal \\ (2) Dão Sul - Sociedade Vitivinícola, S.A., Quinta das Sarzedas, 3430-909 Carregal do Sal, Portugal
}

Submitted for publication: October 2011

Accepted for publication: January 2012

Key words: mannoproteins, white wine, tartaric stabilisation, bentonite, gelatine

\begin{abstract}
Limpidity is a major quality attribute in white wine appreciation. After alcoholic fermentation and ageing, white wines are normally subjected to protein and tartaric stabilisation, followed by filtration. The impact of bentonite and gelatine fining and cold static tartaric stabilisation on the mannoprotein content of two white wines was studied. All treatments promoted a decrease in the content of mannoproteins. Bentonite fining largely affected the mannoproteins with the highest molecular weight, as did cold static tartaric stabilisation and gelatine fining.
\end{abstract}

\section{INTRODUCTION}

Mannoproteins are one of the major polysaccharide groups found in wines (Feuillat, 2003) and originate from Saccharomyces cerevisiae yeast cell walls (Klis et al., 2002). They are known for several important interactions and properties in wines, having the ability to inhibit the crystallisation of tartaric salts (Moine-Ledoux \& Dubourdieu, 2002), prevent protein haziness (Waters et al., 1994), interact with phenolic compounds (Vasserot et al., 1997; Escot et al., 2001; Riou et al., 2002; Poncet-Legrand et al., 2007) and reduce red wine astringency (Guadalupe et al., 2007, 2010), enhance and interact with some wine aromas (Chalier et al., 2007), enhance the growth of malolactic bacteria (GuillouxBenatier et al., 1995), promote flocculation in sparkling wines (Nunez et al., 2006) and adsorb ochratoxin A (Baptista et al., 2004).

Mannoproteins are composed of 10 to $20 \%$ protein and 80 to $90 \%$ D-mannose, linked to residues of D-glucose and $\mathrm{N}$-acetylglucosamine. The mannose chains are linked in $\alpha-(1 \rightarrow 6),(1 \rightarrow 3)$ and $(1 \rightarrow 2)$, and these chains are linked to the peptidic part by amidic bonds with asparagine residues (ramified N-glucans) or by ether bonds to serine or threonine residues (linear O-glucanes) (Pellerin \& Cabanis, 1998). Mannoproteins can present a negative charge at wine $\mathrm{pH}$ and its charge density depends on its content in phosphate groups (Vernhet et al., 1996). Due to these characteristics, they can establish electrostatic and ionic interactions with other wine compounds.

White wine limpidity is a visual attribute of great importance when evaluating the quality of a wine, both in the bottle and in a glass. Wine haziness derived from the presence of unstable grape-derived proteins and tartaric salts constitutes two major issues that the winemaker has to consider when processing the wine in the winery and prior to bottling. Bentonite fining and cold tartaric stabilisation are two treatments largely used in the winery with the objective to stabilise proteins and tartaric salts respectively. Vernhet et al. (1999b) found that mannoproteins associated with tartrate precipitates deposited on stainless steal vessels during cold stabilisation, indicating their possible role in inhibiting crystal growth. Both protein and tartaric stabilisation treatments are normally followed by wine filtration in order to remove any particles in suspension. Wine polysaccharides are known for fouling filtration material such as microporous aluminium membranes (Belleville et al., 1990, 1992) due to their structure and molecular weight distribution. Vernhet et al. (1999a) observed that mannoproteins induced a decrease in the flux through a microfiltration membrane, although the flux decline during wine microfiltration is related more to the content of different polysaccharides and less to the total polysaccharide content. Vernhet et al. (1997) verified that the adsorption of mannoproteins to microfiltration membranes depended on membrane surface properties and that it decreased as surface polarity increased due to unfavourable polar interactions.

As fining and stabilisation are essential procedures in the process of producing white wine, the aim of this work was to evaluate the impact of bentonite and gelatine fining, diatomaceous earth filtration and cold static tartaric stabilisation on the wine mannoprotein content and profile, as there are very few works that have evaluated the variations

*Corresponding author: jricardosil@isa.utl.pt

Acknowledgments: The authors would like to thank Fundação para a Ciência e Tecnologia for the A. Rodrigues PhD grant (SFRH/BDE/15598/2006) 
in mannoprotein nature and content during the winemaking process. In order to achieve this objective, two white wines subjected to different technological pathways according to the process design of the Dão Sul winery were studied. Both wines were made with Encruzado (Vitis vinifera L.) grapes and came from the same starting fermentation lot and were subjected to yeast lees stirring. One wine was aged in oak wood barrels and the other one was aged in stainless steel equipped with oak wood staves. The wine aged in oak wood barrels was subjected to bentonite fining, followed by diatomaceous earth filtration and cold static tartaric stabilisation. The wine aged in stainless steel was subjected separately to bentonite and gelatine fining.

\section{MATERIALS AND METHODS}

All chemicals used were of analytical reagent grade.

\section{Wines}

The Encruzado (Vitis vinifera L.) grapes from Dão Sul Sociedade Vitivinícola, S.A. were harvested in the Dão Region of Portugal. After de-stemming and crushing in a pneumatic press, the free-running juice was cooled to $5{ }^{\circ} \mathrm{C}$ and transferred to a stainless steel vessel with the addition of a preparation of commercial pectinolytic enzymes. The must was allowed to settled for 24 hours, after which it was decanted into a stainless steel vessel $(10000 \mathrm{~L})$. The must was inoculated with a commercial active dry yeast preparation and fermented at 15 to $18{ }^{\circ} \mathrm{C}$ for three weeks. When the density reached $1.060 \mathrm{~g} / \mathrm{cm}^{3}$, part of the must-wine $(3000$ L) was transferred to French oak wood barrels with medium toast $(225 \mathrm{~L})$, where it finished fermentation. The rest of the must-wine $(6000 \mathrm{~L})$ finished fermentation in the stainless steel vessel with French oak wood staves with medium toast. At the end of the fermentation, both wines were subjected to a programme of stirring the lees (bâtonnage), described as following: stainless steel wine - introduction of foodgrade nitrogen through the bottom tap of the vessel at $5 \mathrm{~L} /$ min flow rate for $5 \mathrm{~min}$; barrel wine - manual stirring with a stainless steel stick for 30 seconds per barrel. The bâtonnage took place in both wines at an interval of two to three days during one month after the end of alcoholic fermentation. The lees were then allowed to settle until being stirred once again, 100 days after the end of alcoholic fermentation. Both wines were separated from the lees four months after the end of alcoholic fermentation, constituting the first analysed samples for each trial (barrel aged wine - VBT; stainless steel aged wine - VIT). The two wines were analysed for ethanol content, $\mathrm{pH}$, volatile acidity, titratable acidity and free and total $\mathrm{SO}_{2}$ according to the Organisation International de la Vigne et du Vin official methods (OIV, 2006). The wines' chemical parameters were the following: VBT: alcohol content $13.0 \% \mathrm{v} / \mathrm{v}$, titratable acidity $6.2 \mathrm{~g} / \mathrm{L}$ expressed in tartaric acid, volatile acidity $0.3 \mathrm{~g} / \mathrm{L}$ expressed in acetic acid, $\mathrm{pH} 3.3,20 \mathrm{mg} / \mathrm{L}$ of free $\mathrm{SO}_{2}, 95 \mathrm{mg} / \mathrm{L}$ of total $\mathrm{SO}_{2}$; VIT: alcohol content $13.3 \% \mathrm{v} / \mathrm{v}$, titratable acidity $6.3 \mathrm{~g} / \mathrm{L}$ expressed in tartaric acid, volatile acidity $0.3 \mathrm{~g} / \mathrm{L}$ expressed in acetic acid, $\mathrm{pH} 3.2,30 \mathrm{mg} / \mathrm{L}$ of free $\mathrm{SO}_{2}, 83 \mathrm{mg} / \mathrm{L}$ of total $\mathrm{SO}_{2}$. The wine aged in barrels was subjected to two sequential trials. The first one consisted of subjecting the VBT to bentonite fining $(0.2 \mathrm{~g} / \mathrm{L})$, with five days of contact time, followed by diatomaceous earth filtration, in order to obtain a wine with a turbidity of 1 NTU. The bentonite that was used was an activated bentonite. The earth filtration was made up of a pre-coat of cellulose with a permeability of 0.07 Darcy and a calcinated diatomaceous earth with a permeability of 5.5 Darcy, followed by a calcinated diatomaceous earth with a permeability of 0.3 Darcy. A wine sample was kept at this step of the process for further mannoprotein characterisation analysis, constituting sample VB1. The VB1 wine was then subjected to cold static tartrate stabilisation at $4{ }^{\circ} \mathrm{C}$ for one month, after which a sample of wine was kept for further mannoprotein characterisation analysis, constituting sample VB2.

The wine aged in stainless steel was subjected to two different trials in parallel. The first one consisted of adding $0.3 \mathrm{~g} / \mathrm{L}$ of bentonite to wine VIT, with seven days' contact time. After fining, a sample of the wine was kept for further mannoprotein characterisation analysis, constituting sample VI1. The second trial consisted of adding $0.3 \mathrm{~g} / \mathrm{L}$ of gelatine to wine VIT, also with seven days' contact time. After this procedure, a sample of wine was kept for further mannoprotein characterisation analysis, constituting sample VI2.

Separation and purification of total colloids in the wines A volume of $10 \mathrm{~L}$ of wine was concentrated by ultrafiltration using an Ultrafiltration Millipore system (Millipore, Massachusetts, USA) equipped with a Masterflex EasyLoad I/PTM Model 77410-00 pump (Cole-Parmer's Masterflex, Illinois, USA) and a regenerated cellulose cartridge (Millipore Prep/Scale ${ }^{\mathrm{TM}}$-TFF) with a membrane area of $0.23 \mathrm{~m}^{2}$ and a $10 \mathrm{kDa}$ cut-off. The operation ran in concentration mode at 1.2 bar and room temperature, adding de-salted water to the sample until the sample conductivity dropped to $1000 \mu \mathrm{S} / \mathrm{cm}$ and the final volume was $1.5 \mathrm{~L}$. The process was monitored with a Denver Instrument Model 220 conductivimeter (Denver Instrument, New York, USA). The concentrated wine was subjected to ethanol precipitation by adding twice the volume of cold ethanol to the concentrate at $4^{\circ} \mathrm{C}$. The mixture was allowed to precipitate for $36 \mathrm{~h}$, after which it was centrifuged at $1500 \mathrm{rpm}$ for $10 \mathrm{~min}$. The total colloids were recovered and freeze-dried for $48 \mathrm{~h}$ and the resulting powder was subjected to mannoprotein isolation.

\section{Mannoprotein isolation and characterisation}

A centrifuged solution of total colloids at $1 \mathrm{~g} / \mathrm{L}$ was injected into a Concanavalin-A Sepharose 4B (GE Healthcare BioSciences, Uppsala, Sweden) packed column (100 x $10 \mathrm{~mm})$ and eluted with a sodium acetate-HCL $50 \mathrm{mM} \mathrm{pH} \mathrm{5.6,} \mathrm{NaCl}$ $150 \mathrm{mM}, \mathrm{CaCl}_{2} 1 \mathrm{mM}, \mathrm{MgCl}_{2} 1 \mathrm{mM}$ and $\mathrm{MnCl}_{2} 1 \mathrm{mM}$ buffer solution at $0.8 \mathrm{~mL} / \mathrm{min}$, monitored by a refraction index and a $254 \mathrm{~nm}$ wavelength detectors as described by Gonçalves et al. (2002). The bound fraction was eluted with the same buffer solution, added with methyl $\alpha$-D-mannopyranoside $500 \mathrm{mM}$. The bound fraction was dialysed against water for seven days at $4^{\circ} \mathrm{C}$ and freeze-dried. The Concanavalin- $\mathrm{A}$ bound sample $(1 \mathrm{~g} / \mathrm{L})$ was injected into an FPLC system equipped with a Pharmacia LKB Pump P-500, a 12HR 10/30 FPLC size-exclusion column (GE Healthcare BioSciences, Uppsala, Sweden) and eluted with an ammonium 
acetate $0.3 \mathrm{M}$ buffer solution at $0.5 \mathrm{ml} / \mathrm{min}$, and monitored by a Perkin-Elmer LC-30 RI refractive index detector (Perkin-Elmer, Massachusetts, USA), modified with an LED (light-emitting diode) light source (Cromolab, Queijas, Portugal) and a Knauer WellChrom Spectro-Photometer K-2501 (Knauer, Berlin, Germany) wavelength detector at $254 \mathrm{~nm}$. Calibration of the system was performed with P-82 Pullulan standards (Showa Denko K.K., Kanagawa, Japan). The selected fractions were collected after the FPLC in a Pharmacia Fraction Collector FRAC-100 (GE Healthcare Bio-Sciences, Uppsala, Sweden). The Concanavalin-Abound sample was injected into the FPLC system several times in order to achieve enough quantity of each fraction for further analysis.

The total protein content was determined as described by Lowry et al. (1951) using bovine serum albumin fraction V (Sigma-Aldrich, Missouri, USA) for the calibration curve. The total polysaccharide content was determined with the phenol-sulphuric method as described by Dubois et al. (1956) using glucose (Panreac, Barcelona, Spain) for the calibration curve. The carbohydrate composition was determined by gas chromatography after derivatisation of the samples into their alditol acetates according to Albersheim et al. (1967). An amount of $100 \mu \mathrm{L}$ of a $\mu$-inositol solution $(1 \mathrm{mg} / \mathrm{mL})$ and $1 \mathrm{ml}$ of trifluoroacetic acid $2 \mathrm{M}$ were added to $1 \mathrm{~mL}$ of polysaccharide solution $(1 \mathrm{mg} / \mathrm{mL})$. After hydrolysis at $120^{\circ} \mathrm{C}$ for 75 minutes, the mixture was washed with $5 \mathrm{ml}$ of water and dried. Then, $500 \mu \mathrm{L}$ of a saturated sodium borohydride solution in ammonia were added and the mixture was allowed to react for two hours at room temperature. The reaction was stopped by adding some drops of glacial acetic acid and the mixture was washed with $5 \mathrm{~mL}$ of a solution of $1 \% \mathrm{HCl}$ in methanol and dried. This was followed by the addition of 150 $\mu \mathrm{L}$ of pyridine and $150 \mu \mathrm{L}$ of acetic anhydride to the mixture, which was left to react for $12 \mathrm{~h}$ at room temperature. The tubes were put in an ice bath and the reaction was stopped by adding a drop of water to each tube. The mixture was washed with $5 \mathrm{~mL}$ of water, followed by $1 \mathrm{~mL}$ of ethanol, and dried. The alditol acetates were extracted to $200 \mu \mathrm{L}$ by chloroform and were quantified in a CE Instruments GC 8000 Top gas chromatographer (Thermo Fisher Scientific, Milan, Italy) equipped with a capillary column Zebron ZB-Wax 1060 x $0.25 \mathrm{~mm}, 0.25 \mu \mathrm{m}$ film (Phenomenex, California, USA) and an FID detector. The column temperature was initially set at $220^{\circ} \mathrm{C}$ for $4 \mathrm{~min}$ and raised to $235^{\circ} \mathrm{C}$ at $10^{\circ} \mathrm{C} / \mathrm{min}$, maintaining this temperature for $5 \mathrm{~min}$. Hydrogen was used as carrier gas at $1 \mathrm{~mL} / \mathrm{min}$. $\mu$-Inositol was used as the internal standard and the quantification of sugars was done after determination of each sugar response factor using pure sugars for this purpose.

\section{RESULTS AND DISCUSSION}

In order to study if there was any change in the wine mannoproteins during the fining and stabilisation treatments, the relative mannoprotein quantities found in the total colloids were evaluated. Fig. 1 shows the relative mannoprotein content in the total colloids of each modality.

The mannoproteins in the oak barrel-aged wine (VBT) at the end of the ageing process and before the fining treatments represented $73.7 \%$ of the wine total colloids. In the wine
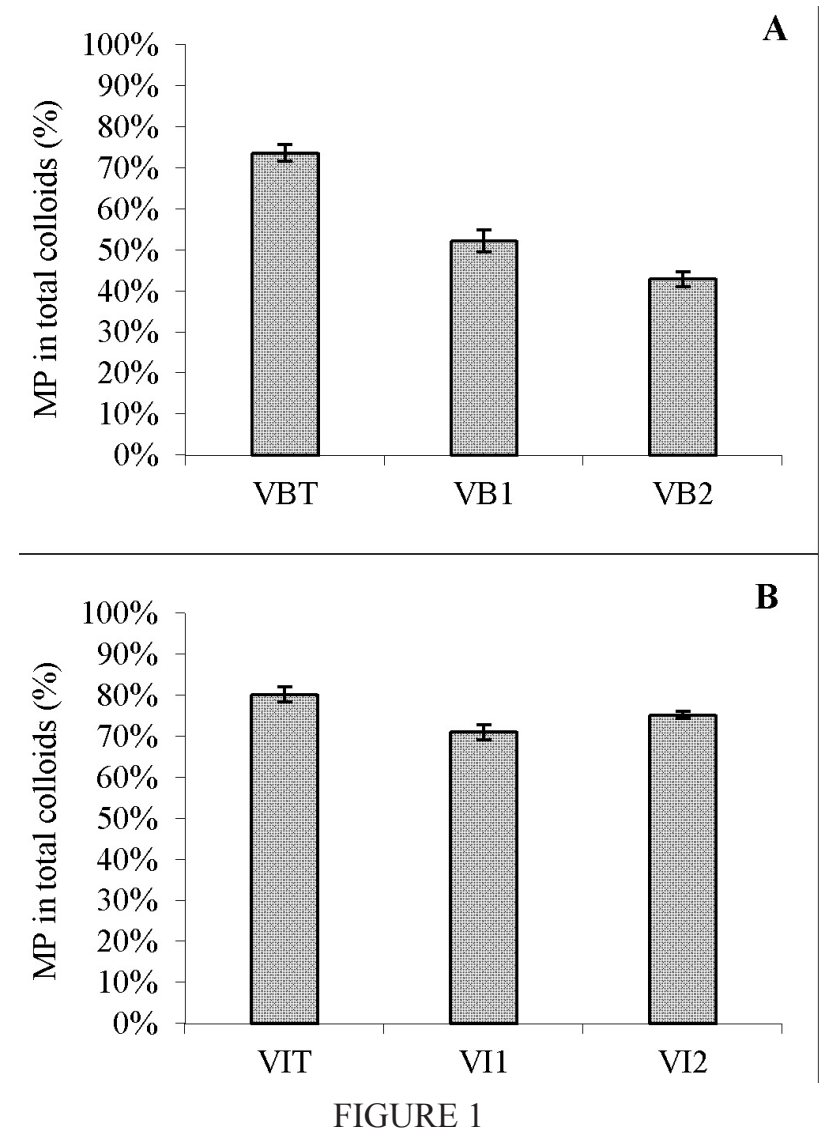

Mannoprotein (MP) content of wine total colloids in A: wine at the end of barrel ageing (VBT), after bentonite fining and diatomaceous earth filtration (VB1), followed by cold tartaric stabilisation (VB2), and B: wine at the end of stainless steel ageing (VIT), after bentonite fining (VI1) and after gelatine fining (VI2).

from the end of the stainless steel ageing process (VIT), the mannoproteins represented $80.3 \%$ of the wine total colloids. The molecular weight distribution of the mannoproteins was similar in the two wines, although the mannoprotein content was slightly higher in the stainless steel-aged wine. After bentonite fining and diatomaceous earth filtration of the VBT (VB1), the mannoprotein content represented 52.3\% of the wine total colloids, which amounted to a decrease of $21.4 \%$. After the cold tartaric stabilisation of VB1 (VB2), mannoproteins represented $43.0 \%$ of the wine total colloids, a decrease of $9.3 \%$ when compared with VB1. The bentonite treatment, followed by the diatomaceous earth filtration and cold tartaric stabilisation, applied to the barrel-aged wine promoted a decrease of $30.7 \%$ in the mannoprotein content from the starting wine (VBT) until the wine after cold tartaric stabilisation (VB2). In the stainless steel-aged wine, this value decreased after bentonite fining (VI1) and mannoproteins represented $71.1 \%$ of the total colloid content. It seems that the mannoproteins of the stainless steel wine interacted with bentonite, as there was a decrease of $8.6 \%$ from VIT to VI1. In the wine treated with gelatine (VI2), mannoproteins represented $75.3 \%$ of the total wine colloids. Gelatine promoted a smaller decrease in the mannoprotein content in the total colloids, corresponding to $5 \%$. The chemical characterisation of the concanavalin-A-adsorbed polysaccharides is represented in Table 1. 
Concerning the concentration of concanavalin-Abound polysaccharides in wine, it was possible to observe a decrease in this value between each step of the technological procedures applied to this wine, both for the barrel wine and the stainless steel wine. Concerning the gelatine-treated sample it was not possible to achieve the correct value, as there was an over-fining of this oenological product, resulting in an enhancement of the final concentration in the wine. The polysaccharide composition indicated that mannoproteins were the major polysaccharide present in the concanavalin-A-retained fraction in all trials. Mannose represented the main sugar and the protein percentage was relatively small. The MP 131 and MP 17 were analysed for all the wines and the results presented are the average of all the obtained fractions. The results shown are the means of all samples, as the results were very similar. The molecular weight distribution of wine mannoproteins is represented in Fig. 2.

There were two well-differentiated polysaccharide fractions in the barrel-aged wine modalities as well as in the stainless steel-aged wine modalities. The average molecular weight of each fraction was $131 \mathrm{kDa}$ for the first eluted

\section{TABLE 1}

Characterisation of concanavalin-A retained polysaccharides in terms of wine concentration $(\mathrm{mg} / \mathrm{L})$, polysaccharides $(\%)$, proteins $(\%)$ and residual sugars $(\%)$. Man = mannose, $\mathrm{Glu}=$ glucose, $\mathrm{Gal}=$ galactose .

\begin{tabular}{|c|c|c|c|c|c|c|c|c|c|c|c|c|c|}
\hline \multirow{2}{*}{$\begin{array}{c}\text { Sample } \\
\text { VBT }\end{array}$} & $\begin{array}{c}\text { Total Con-A Bound } \\
\text { Polysaccharides } \\
\text { (mg/L) }\end{array}$ & Polysaccharides & \multicolumn{3}{|c|}{ Proteins } & \multicolumn{3}{|c|}{ Man } & \multicolumn{3}{|c|}{ Glu } & \multicolumn{2}{|c|}{ Gal } \\
\hline & $8.9 \pm 0.2$ & $94.2 \% \pm 0.3 \%$ & $5.8 \%$ & \pm & $0.3 \%$ & $97.0 \%$ & \pm & $0.1 \%$ & $0.9 \%$ & \pm & $0.0 \%$ & $2.0 \%$ & $\pm 0.0 \%$ \\
\hline VB1 & $7.9 \pm 0.4$ & $89.8 \% \pm 0.5 \%$ & $10.2 \%$ & \pm & $0.5 \%$ & $92.4 \%$ & \pm & $0.4 \%$ & $1.9 \%$ & \pm & $0.0 \%$ & $5.6 \%$ & $0.3 \%$ \\
\hline VB2 & $3.3 \pm 0.0$ & $95.3 \% \pm 0.1 \%$ & $4.7 \%$ & \pm & $0.1 \%$ & $93.4 \%$ & \pm & $0.3 \%$ & $0.5 \%$ & \pm & $0.1 \%$ & $5.7 \%$ & $0.8 \%$ \\
\hline VIT & $9.3 \pm 0.2$ & $95.2 \% \pm 0.3 \%$ & $4.8 \%$ & \pm & $0.3 \%$ & $98.3 \%$ & \pm & $0.4 \%$ & $0.6 \%$ & \pm & $0.0 \%$ & $1.2 \%$ & $0.3 \%$ \\
\hline VI1 & $8.9 \pm 0.3$ & $96.0 \% \pm 0.0 \%$ & $4.0 \%$ & \pm & $0.0 \%$ & $99.3 \%$ & \pm & $0.3 \%$ & $0.5 \%$ & \pm & $0.2 \%$ & $0.1 \%$ & $0.2 \%$ \\
\hline VI2 & $\mathrm{a}$ & $94.0 \% \pm 0.0 \%$ & $6.0 \%$ & \pm & $0.0 \%$ & $97.6 \%$ & \pm & $1.5 \%$ & $0.9 \%$ & \pm & $0.7 \%$ & $1.5 \%$ & $0.9 \%$ \\
\hline
\end{tabular}

VBT: Barrel-aged wine; VB1: Barrel-aged wine after bentonite fining and diatomaceous earth filtration; VB2: VB1 wine after static cold tartaric stabilisation; VIT: Stainless steel-aged wine; VI1: Stainless steel wine after bentonite fining; VI2: stainless steel wine after gelatine fining. $\mathrm{a}$ - the results obtained reflect an over-fining with gelatine.

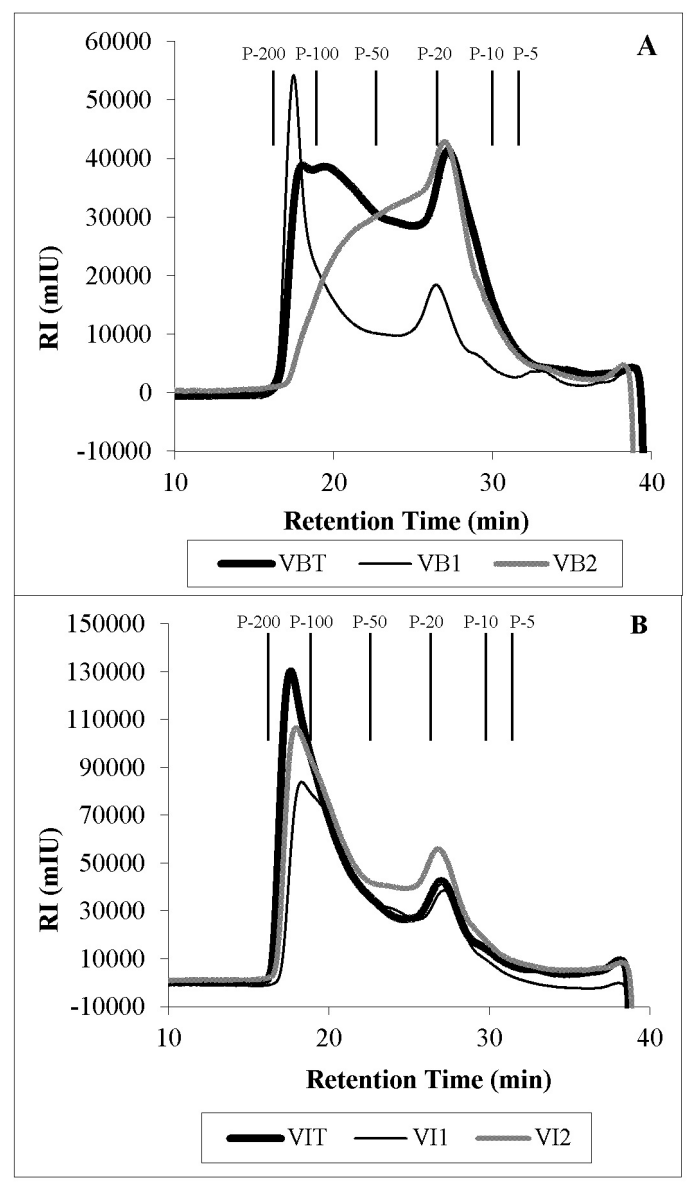

FIGURE 2

Molecular weight distribution of the concanavalin-A column-retained fractions of the white wine polysaccharides by FPLC on a Superose 12HR column, with the elution of the pullulan standards. A: wine at the end of barrel ageing (VBT), after bentonite fining and diatomaceous earth filtration (VB1) and followed by cold tartaric stabilisation (VB2), and B: wine at the end of stainless steel ageing (VIT), after bentonite fining (VI1) and after gelatine fining (VI2). RI refers to refractive index. 
fraction (MP 131) and $17 \mathrm{kDa}$ for the second eluted fraction (MP 17). Comparing the composition of proteins and sugar residues in each fraction (Table 2) it is possible to conclude that the two fractions corresponded to mannoproteins. Fig. 3 represents the distribution of each molecular weightseparated mannoprotein in the treated wines.

In Fig. 3a it is possible to observe that, in the barrelaged wine with no treatments (VBT) and the wine treated with bentonite and diatomaceous earth filtration (VB1) there was a decrease of $10.3 \%$ in the content of $131 \mathrm{kDa}$ mannoprotein and a decrease of $11.2 \%$ in the content of $17 \mathrm{kDa}$ mannoprotein. The bentonite treatment and the diatomaceous earth filtration had an impact on the wine mannoprotein content, promoting a decrease in both molecular weight-separated mannoproteins. Comparing the mannoprotein content in the total colloids between VB1 and the wine that underwent cold tartaric stabilisation (VB2), it is possible to observe a decrease of $8.5 \%$ in the $131 \mathrm{kDa}$ mannoprotein content and a slight decrease $(0.7 \%)$ in the $17 \mathrm{kDa}$ mannoprotein content. The cold static tartaric stabilisation affected the mannoprotein content, mainly in the highest molecular weight mannoprotein. In the stainless steel-aged wine (Fig. 3b), the bentonite treatment promoted a decrease of $11.9 \%$ in the $131 \mathrm{kDa}$ mannoprotein and a slight increase $(2.7 \%)$ in the $17 \mathrm{kDa}$ mannoprotein. The bentonite fining treatment promoted a decrease in the highest molecular

TABLE 2

Mannoprotein molecular weight separated fraction (MP 131 and MP 17) characterised in terms of its molecular weight (MW), polysaccharides (\%), proteins (\%) and residual sugars (\%).Man = mannose, Glu = glucose, Gal = galactose.

\begin{tabular}{|c|c|c|c|c|c|c|c|c|c|c|c|c|c|c|c|}
\hline \multirow{2}{*}{$\frac{\text { Fraction }}{\text { MP } 131}$} & PM (kDa) & \multicolumn{3}{|c|}{ Polysaccharides } & \multicolumn{3}{|c|}{ Proteins } & \multicolumn{3}{|c|}{ Man } & \multicolumn{3}{|c|}{ Glu } & \multicolumn{2}{|r|}{ Gal } \\
\hline & \pm 12 & $99.1 \%$ & \pm & $0.1 \%$ & $0.9 \%$ & \pm & $0.0 \%$ & $96.2 \%$ & \pm & $3.8 \%$ & $2.4 \%$ & \pm & $1.8 \%$ & $1.4 \%$ & $1.9 \%$ \\
\hline MP 17 & $17 \pm 2$ & $99.3 \%$ & \pm & $0.1 \%$ & $0.7 \%$ & \pm & $0.1 \%$ & $96.4 \%$ & \pm & $2.7 \%$ & $1.1 \%$ & \pm & $0.8 \%$ & $2.6 \%$ & $1.9 \%$ \\
\hline
\end{tabular}

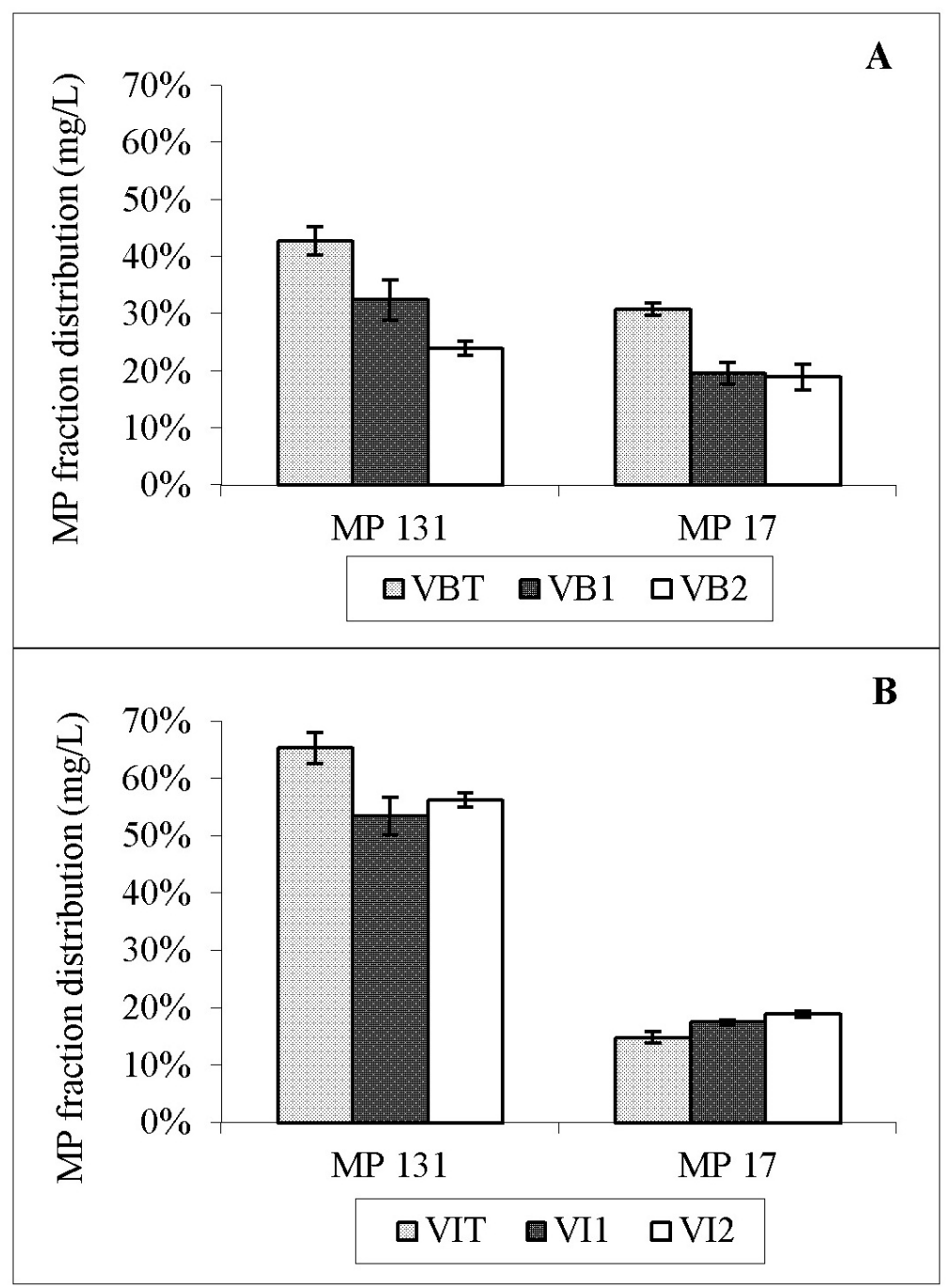

FIGURE 3

Distribution of mannoprotein (MP)-isolated fractions according to their molecular weight in wine total colloids in A: wine at the end of barrel ageing (VBT), after bentonite fining and diatomaceous earth filtration (VB1) and followed by cold tartaric stabilisation (VB2), and B: wine at the end of stainless steel ageing (VIT), after bentonite fining (VI1) and after gelatine fining (VI2). MP 131 and MP 17 refer to wine mannoproteins with an average molecular weight of $131 \mathrm{kDa}$ and $17 \mathrm{kDa}$ respectively, separated by the FPLC system. 
weight mannoprotein, possibly interacting with it. These results are in accordance with those obtained for the barrelaged wine, where it was also possible to observe a decrease in the $131 \mathrm{kDa}$ mannoprotein. The fact that the content of $17 \mathrm{kDa}$ mannoprotein increased slightly in VB1 can be due to analytical variations, corresponding to the maintenance of this low molecular weight mannoprotein after bentonite fining and a reduction in its content after diatomaceous earth filtration. Comparing the stainless steel wine with no treatment (VIT) with the gelatine-treated wine (VI2), there was a decrease of $9.1 \%$ in the $131 \mathrm{kDa}$ mannoprotein and a slight increase of $4.1 \%$ in the $17 \mathrm{kDa}$ mannoprotein. Gelatine had a higher interaction with the higher molecular weight mannoproteins than with the lower molecular weight ones. The interaction seems to be relatively small, as the mannoprotein content in the wine total colloids had a smaller decrease between the VIT and VI2, corresponding to 5\%.

\section{CONCLUSIONS}

The fining and stabilisation treatments applied to the wine aged in barrels as well as the wine aged in stainless steel affected the total mannoprotein content, promoting a decrease in mannoproteins. The mannoprotein distribution showed that the content of both the highest and lowest molecular weight mannoproteins decreased with the applied treatments. In the stainless steel-aged wine, bentonite fining promoted a greater decrease in the total mannoprotein content than in that subjected to gelatine fining.

The bentonite fining essentially affected the highest molecular weight mannoproteins. Concerning the diatomaceous earth filtration combined with the bentonite treatment, it seems that there was no selectivity between high and low molecular weights, as both mannoproteins decreased with this treatment. As bentonite alone affected only the highest molecular weight mannoproteins, it seems as if the earth filtration has no selectivity between high and low molecular weights. The cold static tartaric stabilisation procedure promoted a greater decrease in the highest molecular weight mannoproteins, with almost no impact on the lowest ones. Gelatine fining also promoted a bigger decrease in the highest molecular weight mannoproteins and had no impact on the lowest ones, although it corresponded to the treatment with the lowest impact on the mannoprotein content.

\section{LITERATURE CITED}

Albersheim, P., Nevis, D.J., English, P.D. \& Karr, A., 1967. A method for the analysis of sugars in plant cell-wall polysaccharides by gas liquid chromatography. Carbohydr. Res. 5, 340-345.

Baptista, A.S., Horii, J., Calori-Domingues, M.A., Micotti da Glória, E., Salgado, J.M. \& Vizioli, M.R., 2004. The capacity of mannooligosaccharides, thermolysed yeast and active yeast to attenuate aflatoxicosis. World J. Microbiol. Biotechnol. 20, 475-481.

Belleville, M.P., Brillouet, J.M., Tarodo de la Fuente, B. \& Moutounet, M., 1990. Polysaccharide effects on cross-flow microfiltration of two red wines with a microporous alumina membrane. J. Food Sci. 55, 1598-1602.

Belleville, M.P., Brillouet, J.M., Tarodo de la Fuente, B. \& Moutounet, M., 1992. Fouling colloids during microporous alumina membrane filtration of wine. J. Food Sci. 57, 396-400.
Chalier, P., Angot, B., Delteil, D., Doco, T. \& Gunata, Z., 2007. Interactions between aroma compounds and whole mannoprotein isolated from Saccharomyces cerevisiae strains. Food Chem. 100, 22-30.

Dubois, M., Gilles, K.A., Hamilton, J.K., Rebers, P.A. \& Smith, S., 1956. Colorimetric method for determination of sugars and related substances. Anal. Chem. 28, 350-356.

Escot, S., Feuillat, M., Dulau, L., \& Charpentier, C., 2001. Release of polysaccharides by yeasts and the influence of released polysaccharides on color stability and wine astringency. Aust. J. Grape Wine Res. 7, 153-159.

Feuillat, M., 2003. Yeast macromolecules: origin, composition and enological interest. Am. J. Enol. Vitic. 54, 211-213.

Gonçalves, F., Heyraud, A., Pinho, M.N. \& Rinaudo, M., 2002. Characterization of white wine mannoproteins. J. Agric. Food Chem. 50, 6097-6101.

Guadalupe, Z., Martínez, L. \& Ayestarán, B., 2010. Yeast mannoproteins in red winemaking. Effect on polysaccharide, polyphenolic and color composition. Am. J. Enol. Vitic. 61, 191-200.

Guadalupe, Z., Palacios, A. \& Ayestarán, B., 2007. Maceration enzymes and mannoproteins: a possible strategy to increase colloidal stability and color extraction in red wines. J. Agric. Food Chem. 55, 4854-4862.

Guilloux-Benatier, M., Guerreau, J. \& Feuillat, M., 1995. Influence of initial colloid content on yeast macromolecule production and on the metabolism of wine microorganisms. Am. J. Enol. Vitic. 46, 486-492.

Klis, F.M., Mol, P., Hellingwerf, K. \& Brul, S. 2002. Dynamics of cell wall structure in Saccharomyces cerevisiae. FEMS Microbiol. Rev. 26, 239-256.

Lowry, O.H., Roserbrough, N.J., Farr, A.L. \& Randall, R.J., 1951. Protein measurement with the Folin phenol reagent. J. Biol. Chem. 193, 265-275.

Moine-Ledoux, V. \& Dubourdieu, D., 2002. Rôle des mannoprotéines de levures vis-à-vis de la stabilisation tartrique des vins. Bull. O.I.V. 75, 471482

Nunez, Y., Carrascosa, A., González, R., Polo, M. \& Martinez-Rodriguez, A., 2006. Isolation and characterization of a thermally extracted yeast cell wall fraction potentially useful for improving the foaming properties of sparkling wines. J. Agric. Food Chem. 54, 7898-7903.

OIV, 2006. Recueil des Méthodes Internationales d'Analyse des Vins et Moûts. Organisation International de la Vigne et du Vin, Paris.

Pellerin, P. \& Cabanis, J.C., 1998. Les Glucides. In: Flanzy, C. (Ed) Enologie: Fondements scientifiques et technologiques. Lavoisier, Paris. pp. $40-92$.

Poncet-Legrand, C., Doco, T., Williams, P. \& Vernhet, A., 2007. Inhibition of grape seed tannin aggregation by wine mannoproteins: effect of polysaccharide molecular weight. Am. J. Enol. Vitic. 58, 87-91.

Riou, V., Vernhet, A., Doco, T. \& Moutounet, M., 2002. Aggregation of grape seed tannins in model wine - effect of wine polysaccharides. Food Hydrocol. 16, 17-23.

Vasserot, Y., Caillet, S. \& Maujean, A., 1997. Study of anthocyanin adsorption by yeast lees. Effect of some physicochemical parameters. Am. J. Enol. Vitic. 48, 433-437.

Vernhet, A., Bellon-Fontaine, M.N., Brillouet, J.M., Roesink, E. \& Moutounet, M., 1997. Wetting properties of microfiltration membrane: determination by means of the capillary rise technique and incidence on the adsorption of wine polysaccharide and tannins. J. Membr. Sci. 128, 163174.

Vernhet, A., Dupre, K., Boulange-Petermann, L., Cheynier, V., Pellerin, P. \& Moutounet, M., 1999b. Composition of tartrate precipitates deposited on stainless steel tanks during the cold stabilization of wines. Part I. White wines. Am. J. Enol. Vitic. 50, 391-397.

Vernhet, A., Pellerin, P., Belleville, M.P., Planque, J. \& Moutounet, M., 1999a. Relative impact of major wine polysaccharides on the performance of an organic microfiltration membrane. Am. J. Enol. Vitic. 50, 51-56. 
Vernhet, A., Pellerin, P., Prieur, C., Osmianski, J. \& Moutounet, M., 1996. Charge properties of some grape and wine polysaccharide and polyphenolic fractions. Am. J. Enol. Vitic. 47, 25-30.
Waters, E., Pellerin, P. \& Brillouet, J., 1994. A Saccharomyces mannoprotein that protects wine from protein haze. Carbohydr. Polym. 23, 185-191. 